\title{
Aiming to connect: the business case for diversity in public organizations in The Netherlands Saniye Çelik and Gürkan Çelik
}

\author{
This paper examines the effectiveness of diversity policy and interventions \\ in the Dutch public sector and shows that business case interventions can \\ affect employees' commitment to their organization, contributing to staff \\ retention rates and improving overall performance. Leadership style, as \\ well as organizational culture, are shown to play a crucial role in the \\ effectiveness of the interventions that were analysed.
}

For several decades, the policy in the Dutch public sector has been to stimulate and leverage ethnic cultural diversity in the workforce. The motivation behind the diversity policies has changed over time. Prior to 2000, for example, the main goal was to combat discrimination and offer minority groups equal opportunities in the labour market. At the time, public sector organizations tended to regard diversity as a social issue, and the target group approach of those earlier days needs to be understood against that background. Subsequently, the majority view was that a diversity policy would add value to public organizations. Hence, the arguments used to promote diversity became more commercial and more business-like. In the public sector, diversity in the workforce came to be associated with improved performance levels across the organization as a whole. This approach, also known as 'the business case for diversity' (Çelik, 2015, 2016), was the basis of the research reported in this paper. The concept of the business case has its origins in the private sector. Although the term is also currently used in policy documents published by public organizations, the added value of the business case for diversity in the public sector is not clear. Another unexplored area is how underlying motives translate into daily practice. As a rule, the motives for diversity policy are linked to organizational targets, to be realized using the instrument of intervention.

One overall objective of Dutch public organizations has been to increase the proportion of employees of non-Western descent in their workforces. Examples of interventions include the introduction of a quota system and the use of various recruitment strategies. Interestingly, these interventions have not been very successful. Figures show that the proportion of nonWestern employees has only increased by $2.5 \%$ in the past 15 years (1999-2014), from $4 \%$ to $6.5 \%$, compared to $9.5 \%$ in the total active labour force in 2014. In addition, more employees of non -Western descent are leaving the public sector than those of Western descent. In 2014, $9.6 \%$ of employees of non-Western descent left the public sector, compared to $6.8 \%$ of Dutch descent. Over a period of 15 years, the overall outflow of employees of Dutch descent decreased by approximately $0.7 \%$, while the outflow of employees of non-Western descent increased by approximately $0.2 \%$. In other words, recruiting and retaining employees of non-Western descent has proved challenging. Some public organizations have used interventions to improve their overall performance. These interventions were based on business case motives; however, these interventions were only used in a few cases. Very little is known about the extent to which diversity interventions in the public sector have contributed to the realization of organizational targets.

Our research, therefore, focused on the following question: 
How and to what extent has the business case for diversity been incorporated in and shaped public organizations' policy and interventions, and what determines the impact of those interventions?

\section{Theoretical framework}

In this paper, the notion of diversity policy is approached from a number of angles. Theories of diversity have been developed in three separate disciplines: diversity; public administration; and human resource management (HRM). The present study examines connections with and between these three theoretical fields in greater detail. We used the three diversity perspectives described by Ely and Thomas (2001) in our research:

-Discrimination \& fairness (D\&F).

-Access \& legitimacy (A\&L)

-Integration \& learning (I\&L).

Motives for organizations to strive for diversity in their workforces are mainly equality, legitimacy and productivity.

The D\&F perspective focuses on providing equal opportunities in recruitment and promotion processes, as well as preventing prejudice and discrimination by majority groups. One approach is 'colour blindness' (Podsiadlowski et al., 2013), based on the concept of equality in the treatment and assessment of all individuals, irrespective of their background or ethnicity (Plaut et al., 2009). This differs from D\&F to the extent that colour blindness takes no account of the individual's cultural background and is based only on the premise that the right person be hired in the right place, irrespective of his or her background. The A\&L and I\&L perspectives can both be regarded as representing the business case for diversity, as they strongly emphasise the advantages of diversity for the organization as a whole. The A\&L perspective is primarily aimed at increasing the legitimacy and public profile of an organization in a diverse society in order to better meet the needs of the people in that society. From the I\&L perspective, diversity contributes to increasing creativity and innovation in an organization, contributing to and stimulating that organization's success. Another area of clear overlap with the business case for diversity is the theory of representative bureaucracy from the field of public administration, in which the added value of diversity is linked to the organization's relationship with society at large and the people who live in it. In the academic literature on representative bureaucracy, a distinction has been drawn between passive and active representation (Mosher, 1968; Selden et al., 1998; Dolan and Rosenbloom, 2003). Passive representation relates to the characteristic features of civil service at all levels of public administration and refers to how, demographically speaking, this civil service is a reflection of society as a whole (Groeneveld and Steijn, 2013). Passive representation is closely connected to the D\&F perspective on diversity. In both cases, the focus is purely on the incidence among government personnel of people with certain demographic features that are representative of the community they serve. In both D\&F and passive representation, emphasis is placed on offering equal opportunities. Elements of the A\&L perspective are also embedded in passive representation, embodying the idea that government bureaucracies are accessible to all and that no group is excluded. Nevertheless, the A\&L perspective is much closer in spirit to active representation, which sees a representative civil service workforce as a tool for responding appropriately to diversity in the wider society (Bailey, 2004; Groeneveld and Van de Walle, 2010). Active representation assumes that, by actively seeking to represent different groups in society, it will be easier to incorporate the different values and norms held by those groups when developing new policy (Denhardt and DeLeon, 1995; Sowa and Selden, 2003). Active representation and the A\&L perspective share the underlying idea that diversity will allow governments to better anticipate different public interests, thereby improving the legitimacy and effectiveness of government action.

A third and final area of overlap with the business case for diversity is the field of HRM. On the whole, the HRM literature offers little on the topic of diversity or more generally on the sociodemographic differences between people. In HRM, personnel are regarded as the human capital needed for organizational success, to be used for their specific knowledge, skills and competencies (Boselie, 2002). This view aligns with the idea of managing differences in an organization and underpins the business case philosophy. Increasingly, academic HRM literature has focused on managing differences in the organization, thus introducing the concept 
of diversity management (Pitts, 2009; Groeneveld and Van de Walle, 2010), which is defined as the deliberate and conscious effort to stimulate a diverse workforce and manage differences in order to achieve better organizational results (Ely and Thomas, 2001; Pitts, 2009; Groeneveld, 2011). Like the I\&L perspective, and in line with Cox and Blake (1991), diversity management is based on the idea that differences between employees should be effectively exploited to foster creativity and innovation in the teams and the organization (Çelik et al., 2014; Meerman et al., 2016; Vos et al., 2016).

\section{Research design and methods}

The research presented in this paper is a compilation of four empirical studies, which together attempt to answer the central research question. The first two studies focused on the organizational level. The first study addressed the shift in the Dutch public sector, away from a target-group approach to diversity policy towards a business case approach. The paper discusses the extent to which the Dutch central government has influenced policies and interventions in public organizations at the national level. The second study focused on how the business case for diversity tends to be staged in the public domain. The other two studies related to the second part of our research question, illuminating the effect of diversity interventions on levels of commitment and engagement among public sector employees. The third and fourth studies addressed the influence of organizational culture and of managers on the effects of intervention on staff commitment. Figure 1 illustrates our research model. In the first two studies, the method used was the case study, in which a total of 31 semistructured qualitative interviews were conducted with civil servants and community members. Studies three and four involved a large-scale survey of public sector employees involving 27,167 employees during the period from 12 April 2011 to 26 April 2011. Of these, 11,557 people completed the questionnaire- a response rate of $42.5 \%$. Approximately one million people work in the Dutch public sector. These areas can be divided into three main categories:

o Public administration (national government, municipalities, provinces, judiciary, water supply authorities).

o Education and science (primary education, secondary education, vocational education, professional higher education, academic higher education, research institutes, university medical centres).

o Security (defence and police).

\section{Research results}

Study 1: To what extent does the Dutch government influence the diversity perspectives in public organizations as well as the diversity interventions used?

To address this question, the study focused on the perspectives and interventions introduced by three consecutive governments in The Netherlands during the period 2009-2013 and the public sector areas concerned (Çelik, 2014). It emerged that ways of thinking about diversity in the public sector have undergone a huge transformation. Initially, the emphasis was on

Figure 1. Research model. 


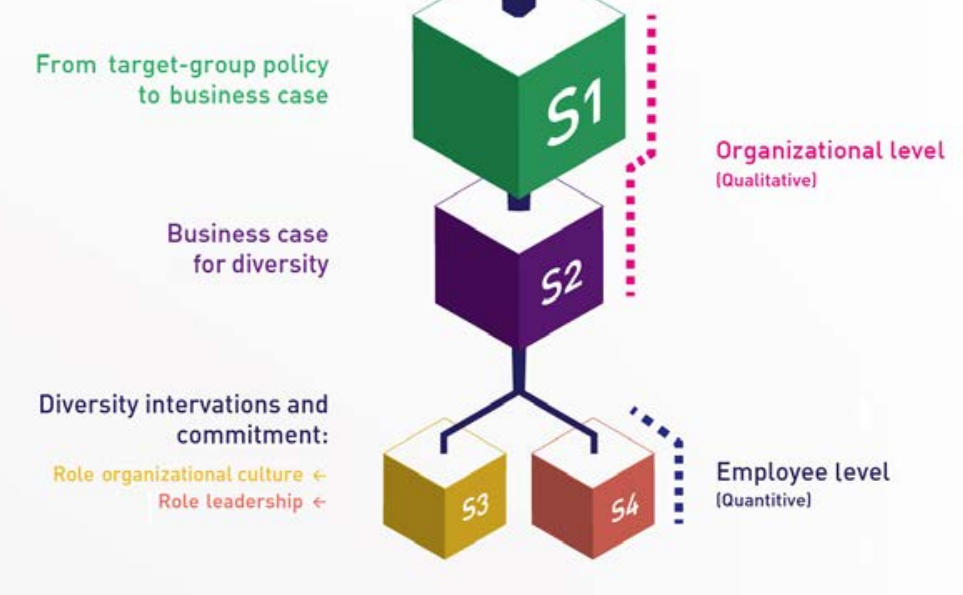

providing equal opportunities; however, the focus is now increasingly on ensuring diversity in the workforce and leveraging organizational performance-the business case for diversity.

Study 2: How do public organizations implement the concept of the business case for diversity? The second study looked at the ways that the business case for diversity was actually being implemented in the public sector (Çelik, 2015). Public and private organizations can have entirely different ideas about the concept of diversity and, therefore, they can differ in their approach to the business case for diversity. Private organizations generally emphasise economic motives, while public organizations are more likely to view diversity in terms of their organization's legitimacy. In comparison to private organizations, public organizations tend increasingly to inhabit a more diverse spectrum of diversity policy. The second study demonstrated that the business case for diversity received more attention in public organizations that operate closer to society. The study also found that some public organizations may be trying to implement several business cases at the same time. In this respect, the A\&L concept (i.e. an organization's legitimacy and public profile) is the most prominent business case, although the emphasis can differ across public sector areas. At national government level, for example, the main focus was on making the best possible use of available labour market resources for the benefit of the organization and on ensuring that diversity contributed to the quality and public profile of the government.

In the police service, the stated aim was primarily to be able to respond more swiftly to change in a diverse society.

The second study also found evidence of a new, public specific business case motivated by social responsibility and a desire to establish a sustainable relationship between the government and society. The public sector 'relationship perspective' on diversity has evolved from this, emphasising socially responsible objectives introduced in government organizations and characterized by active investment in long-term relationships between the government and citizens. In this relationship perspective, it is assumed that acknowledging the differences in an organization, all its employees-irrespective of their ethnic background-will ultimately be better able to connect with a wide and diverse range of people in society, making this a new perspective on the business case for diversity in a public context. 
Study 3: What role does organizational culture play in public sector organizations, especially in relation to diversity interventions and employee commitment?

The third study focused on the effects of the most commonly used diversity interventions in the public sector on employee engagement and commitment to their organization. Commitment to an organization was assessed in terms of employees' wanting to leave the organization. It is well known there is a strong relationship between an organization's culture and its staff turnover rates (Van Knippenberg et al., 2004). One of the findings from our study was that business case interventions have been more effective in terms of employee commitment than interventions based on target groups. One such business case intervention was the establishment of a diversity recruitment team to look at new job applications; another was a programme designed to create an open culture. One possible explanation for why these interventions tend to be more effective is that they significantly enhance the inclusivity of the organizational culture. Interventions of this sort were found to strengthen the bond between employees and their organization. So it is reasonable to conclude that an inclusive organizational culture is an important prerequisite for staff engagement and commitment.

Study 4: What is the role of managers in public organizations, especially in relation to diversity interventions and degree of employee commitment?

The fourth study essentially elaborated on study 3 in that it also focused on the effectiveness of the most common public sector diversity interventions. However, in study 4 , the emphasis was on the role of the manager (Çelik et al., 2011). It is well known that leadership style influences how any personnel policy is implemented (Purcell and Hutchinson, 2007). One conclusion that can be drawn from study 4 is that the more transformational the leadership style of an organization, the stronger its employees' commitment to the organization. Managers with a transformational style of leadership are known to be more aware of and open to individual differences, which means that the differences in an organization are more likely to be put to better use. As a consequence, employees will be more engaged and committed, and less likely to leave, irrespective of ethnic background. Study 4 clearly shows that transformational leaders have a positive effect on the inclusiveness of the culture in an organization, which is crucial for effective management of a diverse workforce. In addition, diversity management appears to strengthen the binding of employees with the organization.

Another conclusion from study 4 is that a transformational leadership style means that business case interventions to stimulate employee engagement (including programmes to create an open culture) become redundant. This may be because of the overlap between the characteristics of a transformational manager (for example allowing for individual differences and stimulating a better organizational culture) and certain activities associated with the business case for intervention-again highlighting the importance of interventions aimed at managers and their leadership styles.

\section{Conclusion and discussion}

Public sector organizations in The Netherlands primarily justify their diversity policy on the grounds that differences in organizations add value to those organizations. The business case for diversity is therefore securely rooted in these organizations' way of thinking about diversity. In the public sector, the business case for diversity can take any of the four forms discussed, although they may differ between and in the different public sectors. The first of these relates to efforts to enhance the legitimacy of organizations and anticipate and connect to an increasingly diverse population in society. This is known as the A\&L (access \& legitimacy) perspective and is the most commonly used approach in the Dutch public sector. A second type of business case, directly related to the first, is the labour market approach where the government aims to make the best possible use of labour market potential by attracting a more diverse workforce. At the same time, this approach enables the government to improve its public image in the labour market. The third approach is the I\&L (integration \& learning) business case. By allowing for diversity in the workforce, organizations improve creativity and productivity. The fourth case is 'connecting', where the emphasis is on establishing a sustainable relationship between the government and society, in turn enhancing citizens' trust in their government. This connection business case aims to prevent a rift between the 
government and society, therefore overlapping with the A\&L perspective. In both cases, the focus is on establishing a connection between a public organization and society. More specifically, the connection perspective emphasizes the achievement of the organization's social aims by investing in long-term relationships between the government and society. To this end, the civil service must continually monitor the differing interests of various parties in society, analysing expectations and translating these into government policy. Although public organizations tend to approach the concept of diversity from a business case perspective, this will only rarely be translated into actual interventions. Interventions associated with an organization's affirmative action policy-including the use of quota and/or targets for the inflow and internal mobility of staff from specific target groups-still predominate. This is primarily because interventions by public organizations are subject to and must therefore comply with central government policy and the tendency for central government to drive interventions of this type. This influence is stronger in sectors where central government has direct control, as in the case of government departments and ministries and the police. At the same time, public sector organizations closer to society are more likely to seek to connect to that society and will more readily use the instrument of business case intervention.

However difficult it may be to identify business case interventions, they were found to have a positive effect on employees' commitment to their organization. An inclusive organizational structure was also found to be central to the effectiveness of business case interventions. In addition, the present research shows that a transformational leadership style strengthens employee commitment levels. On that basis, it is reasonable to conclude that more business case interventions and increased attention to elements such as organizational culture and leadership style can contribute to staff retention.

An important contribution of this paper to the academic literature is the insight it provides into the organizational context surrounding diversity policy. Both A\&L and I\&L perspectives were found in the Dutch public sector. At the same time, however, it was found that the implementation of A\&L and I\&L as business cases can differ in emphasis. Whereas the A\&L concept may refer to an organization's image in one sector, it may well be used elsewhere to harness an organization's legitimacy. Another major contribution of this study is identifying the connective perspective as a new public specific form of business case.

This paper also contributes to knowledge about the effectiveness of diversity policy and interventions in the public sector and shows that business case interventions can affect employees' commitment to their organization. Moreover, mediating elements-such as a transformational leadership style and an inclusive organizational culture-were found to have an impact on the effectiveness of interventions. Thus, it would be interesting to study the role of organizational culture and leadership in more detail across a range of diversity interventions.

\section{Implications for aiming to connect}

This paper also has some important lessons for practice. If public organizations want to establish a long-term relationship with the community in which they operate, it is essential that they approach the diversity issue from a connecting point of view, placing greater emphasis on connecting with people and ensuring the appropriateness of interventions. The government is expected to be of service to the community and to realize this responsibility by actively seeking to connect with its citizens. This connecting role of government needs to receive more attention at all levels of public administration, and not just in organizational units in direct contact with the community, such as staff at municipal service desks, police officers patrolling the streets or teachers in front of a class. This connecting role is partly the responsibility of policy-makers, managers and directors who need to build bridges between government and society, not just during policymaking but also during implementation by actively seeking interaction between government and citizens. Managers and directors are key players in this effort; as well as politicians in terms of agenda-setting. Shifts in the social climate present a challenge for diversity policy. Nevertheless, with increasing calls for investment in an inclusive society, this situation presents countless opportunities to create a more connected public sector. 


\section{Acknowledgements}

This paper is based on Saniye Çelik's dissertation research which was completed in 2016 at Leiden University, supervised by Professor S. M. Groeneveld. The support of T. S. Ashikali, a $\mathrm{PhD}$ candidate at Leiden University in aspects of the research is also highly appreciated.

\section{References}

Bailey, M. (2004), Representative bureaucracy: understanding its past to address its future. Public Administration Review, 64, 2, pp. 246- 249.

Boselie, P. (2002), Human Resource Management, Work Systems and Performance: A TheoreticalEmpirical Approach (Erasmus University Rotterdam).

Çelik, G., Vos, M. and Vries, S. de (2014), Verschil benutten in het hoger onderwijs: een integrale, interactieve en iteratieve benadering van organisatieontwikkeling. Tijdschrift voor Hoger Onderwijs, 32, 4, pp. 305-318.

Çelik, S. (2014), Van doelgroepenbeleid naar business case van diversiteit: de invloed van het kabinet op publieke sectoren. Bestuurswetenschappen, 68, 4, pp. 5-33.

Çelik, S. (2015), De business case van diversiteit in een publieke context: de verbindende overheid. Tijdschrift voor HRM, 3, 2, pp. 1-33.

Çelik, S. (2016), Sturen op verbinden. De business case van diversiteit van publieke organisaties (Leiden University).

Çelik, S., Ashikali, T. S. and Groeneveld, S. M. (2011), De invloed van diversiteitsmanagement op de binding van werknemers in de publieke sector. De rol van transformationeel leiderschap. Tijdschrift voor HRM, 14, 4, pp.32-57.

Çelik, S., Ashikali, T. S. and Groeneveld, S. M. (2013), Diversiteitsinterventies en de binding van werknemers in de publieke sector. De rol van een inclusieve organisatiecultuur. Gedrag en Organisatie, 26, 3, pp. 329-352.

Cox, T. and Blake, S. (1991), Managing cultural diversity: implications for organizational competitiveness. Academy of Management Executive, 5, 3, pp. 45-46.

Denhardt, R. and DeLeon, L. (1995), Great thinkers in personnel management. In Rabin, J. (Ed), Handbook of Public Personal Administration (Marcel Dekker), pp. 21-43.

Dolan, J. and Rosenbloom, D. H. (2003), Representative Bureaucracy: Classic Readings and Continuing Controversies (M. E. Sharpe).

Ely, R. J. and Thomas, D. A. (2001), Cultural diversity at work: the effects of diversity perspectives on work group processes and outcomes. Administrative Science Quarterly, 46, 2, pp. 229-273.

Groeneveld, S. M. (2011), Diversity and employee turnover in the Dutch public sector. Does diversity management make a difference? International Journal of Public Sector Management, 24, 6, pp. 594612.

Groeneveld, S. M. and Steijn, B. (2013), Arbeidsmarkt, Werving en Selectie. In Steijn, B. and Groeneveld, S. M. (Eds), Strategisch HRM in de Publieke Sector (Van Gorcum), pp. 77-102.

Groeneveld, S. M. and Van de Walle, S. (2010), A contingency approach to representative bureaucracy: Power, equal opportunities and diversity. International Review of Administrative Sciences, 76, 2, pp. 239-258.

Meerman, M., Van den Broek, L. and Çelik, G. (2016), De kracht van verschil. Van een rondetafelgesprek over methodieken naar een diversiteitsagenda. Tijdschrift voor Management \& Organisatie, 70, 2, pp. 101-114.

Mosher, F. C. (1968), Democracy and the Public Service (Oxford University Press).

Pitts, D. W. (2009), Diversity management, job satisfaction, and performance: evidence from U.S. federal agencies. Public Administration Review, 69, 2, pp. 328-338.

Plaut, V. C., Thomas, K. M. and Goren, M. J. (2009), Is multiculturalism or color blindness better for minorities? Psychological Science, 20, 4, pp. 444-446.

Podsiadlowski, A., Gröschke, D., Kogler, M., Springer, C. and Van der Zee, K. (2013), Managing a culturally diverse workforce: diversity perspectives in organizations. International Journal of Intercultural Relations, 37, 2, pp. 159-175.

Purcell, J. and Hutchinson, S. (2007), Front-line managers as agents in the HRM performance causal chain: theory, analysis and evidence. Human Resource Management Journal, 17, 1, pp. 3-20.

Selden, S. C., Brudney, J. L. and Kellough J. E. (1998), Bureaucracy as a representative institution: towards a reconciliation of bureaucratic government and democratic theory. American Journal of Political Science, 42, 3, pp. 719-744. 
Sowa, J. E. and Selden, S. C. (2003), Administrative discretion and active representation. An expansion of the theory of

representative bureaucracy. Public Administration Review, 63, 6, pp. 700-710.

Van Knippenberg, D., De Dreu, C. K. W. and Homan, A. C. (2004), Work group diversity and group performance: an integrative model and research agenda. Journal of Applied Psychology, 89, 6, pp. 1008-1022.

Vos, M., Çelik, G. and Vries, S. de (2016), Making cultural differences matter? Diversity perspectives in higher education. Equality, Diversity and Inclusion, 35, 4, pp. 1-15.

\section{IMPACT}

This paper provides lessons for public sector organizations needing a stronger connection with the society they serve. Effective diversity policies require agenda-setting from government, a transformational leadership style and an inclusive organizational culture. 